\title{
Community connections: Moving from a culture of caregiving to community building
}

\author{
Ray Schmidt \\ Fairfield County Board of Developmental Disabilities, 7140 Reynoldsburg-Baltimore Road, Pickerington, \\ OH 43147, USA \\ Tel.: +1 614835 2700; E-mail: RSchmidt@fairfielddd.com
}

Revised/Accepted November 2015

\begin{abstract}
.
BACKGROUND: The United States faces a challenge to build on the successes of our predecessors and help every individual thrive in the community. It is a challenge that is fraught with complexities, but programs are being created to address this issue.

OBJECTIVE: This article discusses the development of a software application, referred to as the Community Connection Manager, for professionals to help match people to community contacts as to develop skills in community integration and employment.

CONCLUSION: The Community Connections Manager was created as part of an overall agency redesign to help us prepare to meet the challenges ahead. As we move away from conventional, brick and mortar methods of service provision, we think these community contacts will be the tools we will use to develop and coordinate opportunities for the people we serve. The goal is to help each individual take their chosen place in a community where they are valued for who they are and the contributions they make.
\end{abstract}

Keywords: Community, inclusion, person-centered, individuals with disabilities

\section{Introduction}

In Ohio, and across the nation, we are in the midst of an enormous challenge. The past fifty years witnessed a move from institutions to group homes and sheltered workshops. These programs often helped people earn their first pay, gain self-esteem, and broke the barriers that for years had kept people with disabilities locked away and out of sight. Our challenge is to build on the successes of our predecessors and take the last step: to help each individual find their way in the community we all enjoy. It is a challenge that is fraught with complexities.

In Fairfield County Ohio we began a process to design our new system of service delivery two years ago. Although we understood the needs of the individuals we serve, our process pointed out the challenge of finding, supporting, and sustaining community connections friendly to our cause, and ready to help. This paper discusses the development of a software application for professionals to help match people to community contacts as we develop our skills in community integration and employment.

\section{What is "community"?}

As we started working on the project, it became evident that we did not have a standard definition of the word "community." Some defined it as field trips to a local store or restaurant. This kind of definition only hints at what community can be. It treats the individual as a tourist in someone else's community. A sense of community however takes action. For us, 
the concept of community must be a verb. As we entered the development process, we considered the concept of community this way: "Community is the art of sharing who we are"

We consider community to involve these elements:

- Although a sense of community can happen anywhere, we will focus our strategies to maximize integration outside the walls of our organization.

- Our definition includes the necessity of sharing. Talent and ability, no matter how profound, will not contribute to the community until we share it.

- Our responsibility is to first help people with disabilities to take their chosen place in the community. A related, but equally important goal is to help prepare the community to make this a reality.

\section{Creating the crucible}

For years, we specialized in creating programs to serve people with disabilities. We serve over twelve hundred people, and we have developed programs large and small to achieve our mission. Person Centered Thinking will cause a systemic change in our provision of service. Instead of thinking in terms of groups of people, we must change our focus to the individual. Some professionals argue that good agencies already focus on the individual. We would argue that the difference today is in marshalling all of our resources to meet the unique needs of each individual. In short, we will change the very service we provide on an individual basis. Instead of an individual choosing from a menu of services, there will need to be an infinite number of services, driven by the needs of the individual.

As an agency, we now see part of our responsibility of creating the opportunity for people with and without disabilities to meet and develop their relationship based on common abilities and interests. Where those opportunities do not exist, we will strive to develop the crucible that allows people of all abilities to connect naturally.

\section{Creating a tool}

Employment First and Person Centered Theory require a different way of thinking to be sure, but we also believe it will require a significant change in tools and in the way we deploy our staff to achieve the new mission. As we explored what we would need, we discovered that we had plenty of information about the people we serve, but almost no information about the resources available in the community.

The initial concept of the application was simple; keep track of the people we serve, the resources in the community, and find creative ways to connect the two. We designed the system to keep track of basic demographic information, current placement and program information, and information about the unique needs and desires of the individual. Figure 1 provides an screenshot of the main demographic page of the system. In a similar way, we keep track of the same information for each community contact; where they are located, who have benefited from the relationship in the past, and our experience with each relationship.

A critical variable in our development involved the use of a common set of attributes. We spent a great deal of time developing these attributes and we struggled with the detail we should include. Overly general attributes would produce matches of little significance. Overly concrete attributes would be too rigid and may miss the mark completely. We explored many existing lists of attributes but found that they worked poorly in this application for a variety of reasons. Our final list of attributes are conceptual in nature. We ask simple questions, "Do you like to work alone or with other people?" or "Do you like things to be the same every day or different?" We can then use those general responses to help us find connections that work.

We apply those same attributes to community contacts, but think about them differently. We attach the attributes based on the skills needed for a job, or for the interests of the people already engaged in the activity. For one of the people we serve, we assigned attributes of wanting to be near other people, being personable, and liking change. The result was a placement as a sampler at a restaurant in our local food court. After just a few months, the manager of the establishment found that the individual had connected with many people at the mall, including a group of older people who came to walk every day. On days when the individual was off, the group would often ask where he was. The manager is now one of the strongest partners for our agency, and is a model of how great employment can work.

Attributes play a significant role in both job development and discovery. As soon as we start to populate attributes for an individual (left hand pane of Fig. 2), the computer starts to recommend matches in the right hand pane. The computer assesses fit based 


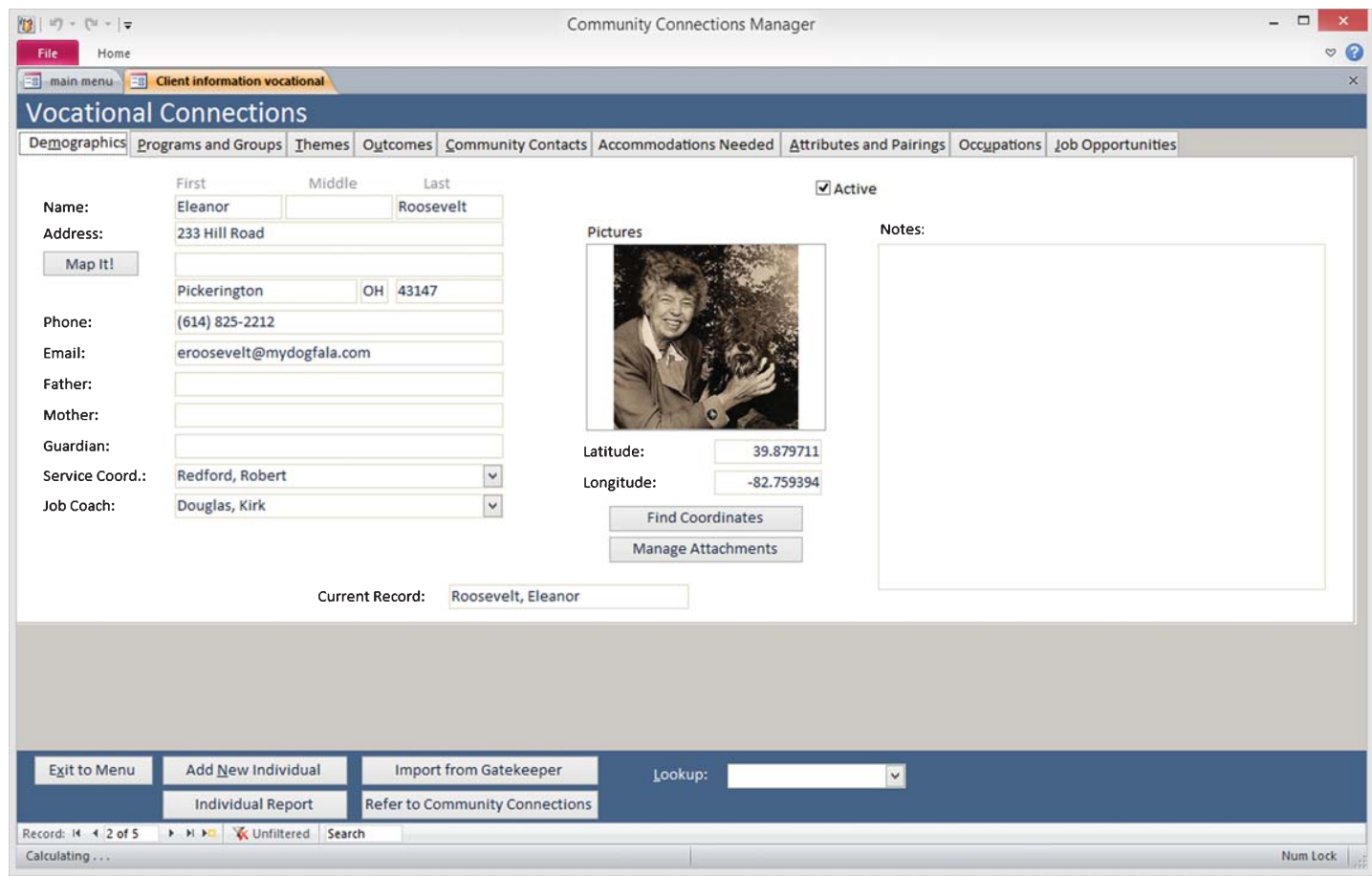

Fig. 1. Main demographic screen from the Community Connections Manager.

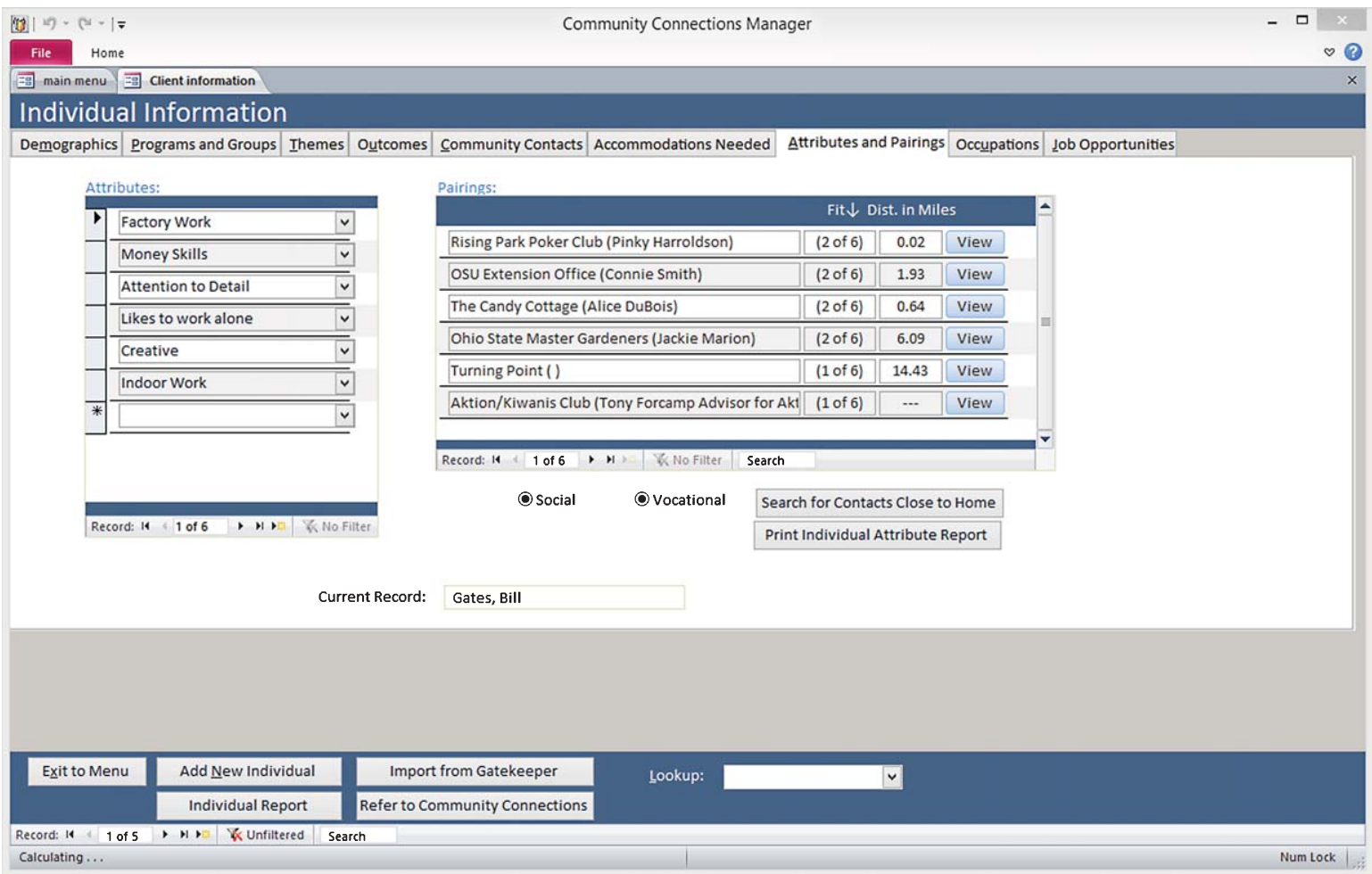

Fig. 2. Attribute Matching Panel from the Community Connections Manager Application. 
on the number of common attributes, and calculates the distance from where the individual lives to the contact. More attributes will result in a more accurate match, but our experience has been that six to eight attributes is an efficient number that creates the optimum number of matches. Again, moderation is the key to effective connections. Too few attributes assigned to an individual will produce a large list matches, but not many useful connections. Too many attributes assigned to a community contact will result in a connection to almost every individual.

\section{Job matching}

Once we developed the initial structure of the software, we explored online resources to aid in job searches. One such resource was the $\mathrm{O}^{*}$ Net database. $\mathrm{O} * \mathrm{Net}$ is a federal resource that tracks vocational data for over eleven hundred occupations. Individuals can select from all of those careers and then link directly to $\mathrm{O}^{*}$ Net to learn more (see Fig. 3). We also learned that other federal resources use the $\mathrm{O}^{*} \mathrm{Net}$ numbering system to coordinate their resources as well. We link to the bureau of labor statistics to gather projection data about each career choice, and Career One-Stop to view videos of over five hundred $\mathrm{O} * \mathrm{Net}$ careers. Finally, we are fortunate in Ohio that our main public job searching website, OhioMeansJobs.com, uses $\mathrm{O} *$ net database codes for searching as well. We seed searches to Ohio Means Jobs using the home address of the individual, and the occupation codes selected during the job matching process. The software then searches for every job within a twenty-mile radius of where the individual lives for the specific jobs they want to find. Since this is a live connection, every time a job developer looks at this matching tool, the newest connections and opportunities display on the screen.

\section{Liaisons}

One of the more interesting challenges we encountered when developing the tool was the idea of how to coordinate our efforts among all of our county resources, two hundred employees, and 165 private providers. We decided to appoint a liaison for each individual community contact. We charge the liaison with coordinating all communication with the

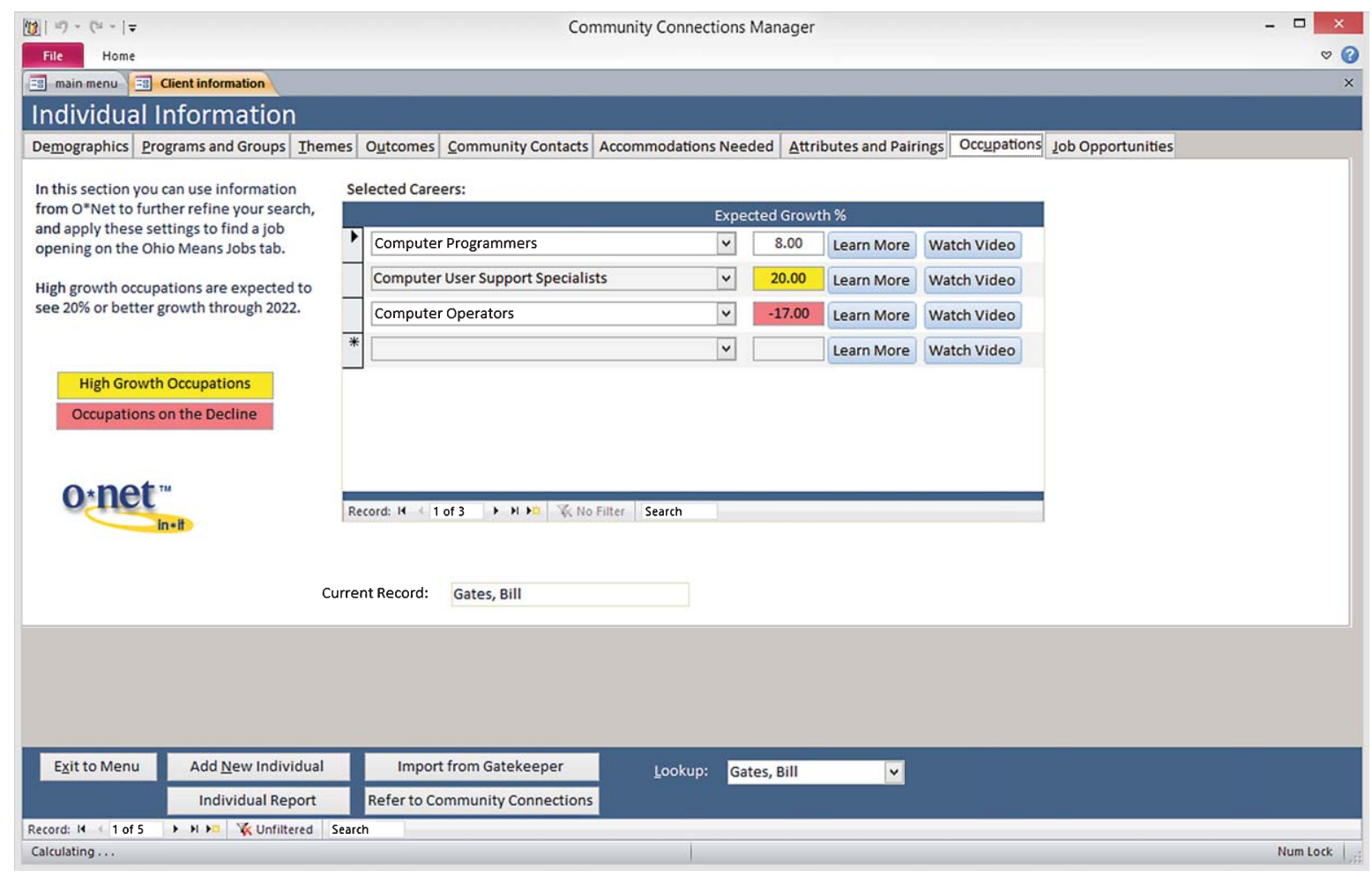

Fig. 3. Job Matching Panel from the Community Connections Manager Application. 
community contact. In addition, the liaison has the responsibility of developing the relationship from a mere acquaintance to a true partner.

\subsection{Building individual communities}

We use similar techniques to make social connections for people as well as vocational. Our belief is that individuals who have social and vocational connections will be more successful. Although attributes are purposely general in nature, some do have a vocational or social focus.

We also use attributes to keep a list of community activities. Individuals can view a list of community activities (both social and vocational), matched to their particular interests. If they find an activity of interest, a simple button click will add that activity to their schedule. They can then print their schedule to plan their month.

Our new definition of service includes helping individuals find a job, create a social life, and find interesting things to do. A key concept is to help only as much as needed, and to fade that assistance as early as possible. Our previous system, although competent, has the unintended consequence of building dependency. There may always be people who need a great deal of our assistance, but our goal must be for people to create lives well beyond the needs of our services.

\section{Reporting}

On our way to helping people make these connections and build their own personal communities, we will gather an incredible amount of information along the way. The information we gain on our relationships with community contacts will help us learn what employers need, and the tolerance level of our community groups. We will track comparative data as well to explore the cost benefits of connecting people in the community vs. placement in a segregated environment. Other data will illustrate the efficacy of our transitional programs, helping us to spend the funding we have more efficiently and with greater intelligence.

\section{Conclusions}

The development of the Community Connections Manager is just part of an overall agency redesign to help us prepare to meet the challenges ahead. It is a tool that we put into the hands of a new group of professionals working to build individual connections and achieve personalized outcomes. Comparing year-to-year performance, we placed sixteen people in competitive employment through the end of October 2014. Looking at the same period in 2015, we assisted twenty-five individuals in successfully finding a job for a $56 \%$ increase in performance. We do not attribute this increase to a single tool or individual, but rather to a significant change in focus. Similar efforts throughout the agency resulted in the creation of 697 new community contacts in a period of just one year. As we move away from conventional, brick and mortar methods of service provision, we think these community contacts will be the tools we will use to develop and coordinate opportunities for the people we serve. The goal is to help each individual take their chosen place in a community where they are valued for who they are and the contributions they make.

\section{Conflict of interest}

None to declare. 